\title{
Removal of Chemical Oxygen Demand (COD) from Domestic Wastewater Using Hybrid Reed Bed System
}

\author{
Omar Hamed Jehawi ${ }^{1,3, a^{*}}$, Siti Rozaimah Sheikh Abdullah ${ }^{1, b}$, Mushrifah Idris ${ }^{2, c}$ \\ Hassimi Abu Hasan ${ }^{1, d}$, Nadya Hussin AL Sbani ${ }^{1, e}$, Nur 'Izzati Ismail ${ }^{1, f}$ \\ ${ }^{1}$ Department of Chemical and Process Engineering, Faculty of Engineering and Built Environment, \\ National University of Malaysia, 43600 Bangi, Selangor Darul Ehsan, Malaysia \\ ${ }^{2}$ Tasik Chini Research Center, Faculty of Science and Technology, National University of Malaysia, \\ 43600 Bangi, Selangor Darul Ehsan, Malaysia \\ ${ }^{3}$ Department of Chemical Engineering, Faculty of Engineering, Al-Mergehb University, Al-Khoms \\ City, Libya \\ aomerjehawi@yahoo.com, 'brozaimah@ukm.edu.my, 'cmushrifahidris@gmail.com, \\ dsimiabuhasan@gmail.com, eneam2009@yahoo.com, 'ezaty_ismail@yahoo.com
}

Keywords: Hybrid reed bed systems, Domestic wastewater; Surface Flow (SF); Vertical Flow (VF), Horizontal Flow (HF).

\begin{abstract}
Hybrid reed bed systems (HRBs) have a good potential for wastewater treatment in developing countries due to its simple operation and low implementation costs. HRBs units were constructed at Bukit Putri, in UKM university campus, Malaysia, of which were planted with Scirpus grossus plants, commonly known as club-rush or bulrush (water loving plants). Generally, HRBs are classified into two categories: surface-flow and subsurface-flow. Both systems are capable of removing Chemical Oxygen Demand (COD) from different types of wastewaters. The aim of this study was to determine the percentage removal of Chemical Oxygen Demand (COD) at different concentration of domestic wastewater by using a HRB systems. This hybrid system was arranged in a serial stages consisting of a surface-flow (SF) bed, followed by a vertical-flow (VF) bed and finally by a horizontal-flow (HF) bed. In the present study, the performance of the HRB on domestic wastewater, particularly on COD, with and without plants was investigated. It is observed that the planted system with Scirpus grossus had performed better than the unplanted system. The result shows that the COD removal varied between 60 and 92\%, depending on the loading rates (53-86 $\mathrm{mg} / \mathrm{L} /$ day). The treatment system was operated for three months in the continuous flow process. Based on the results, it can be concluded that the HRB system ensures a more stable removal of organic pollutants (COD) from domestic wastewaters.
\end{abstract}

\section{Introduction}

People worldwide are demanding for green technology due its simple, safe, and cost-effective features. As one of such technologies, Constructed Wetland $(\mathrm{CW})$ utilizes natural process and only requires simple construction with low maintenance, apart from being eco-friendly $[1,2]$ defined it as a man-made basin engineered to imitate the ecological condition that of natural wetlands for the purpose of treating wastewater in unique biological, physical, and chemical conditions. Conventional high-technology wastewater treatment systems are in many situations not a suitable solution in developing countries because it is not sustainable to install wastewater systems which require guaranteed power supply, replaceable spare parts and a skilled labor for operation and maintenance. Therefore, it is better to use simple and cost-effective technologies like CWs for wastewater treatment.

CW has been widely accepted as a very useful eco-technology, especially for small towns and industries with limited capital to equip themselves with the costly conventional treatment systems [3]. It is a sustainable system because it utilizes natural energy to degrade pollutants, hence the low construction and operational costs as compared to the conventional wastewater treatment system [4]. It is also known as free water surface (FWS) system due to its similarity with the natural systems by having a bed surface for the water to flow and filtered through the available aquatic plants [5]. There 
is another type of constructed system, but it is called sub-surface flow wetland because it is made of lined shallow basin filled with emergent aquatic plants and gravel media [6].

Advancement in CW technology has led to the development of hybrid CW, which is a combination of different $\mathrm{CW}$ systems on various configurations. Compared to the single CW system, the hybrid CW performs wastewater treatment at a higher efficiency, especially if it involves nutrient components. The configurations of hybrid CW may involve combinations of flow rate, Surface Flow (SF), Vertical Sub-Surface Flow (VSSF), and Horizontal Sub-Surface Flow (HSSF).

The main visual feature of $\mathrm{CW}$ is the presence of plants. Plants play an important role in wastewater treatment, both directly and indirectly [7]. Physically, it provides a vast surface area for microbial attachment and growth. In temperate zones, the plant litter acts as a protection against the freezing weather during winter. It has also been established that plants promote aerobic degradation through the oxygen they release to the rhizosphere [8]. However, it has been proven difficult to measure the exact rate of oxygen release and the exact influence on waste treatment are likely different between plants.

Application of constructed wetlands for treatment of household contaminated is new interest in Malaysia. This study is an experimental study, in which the effectiveness of constructed wetland is known to measure the COD of influent and effluent. This paper aims to determine the percentage removal of Chemical Oxygen Demand (COD) at different concentration of domestic wastewater by using (HRBCW).

\section{Materials and method}

\section{Design and operation of Hybrid Reed Bed System}

Hybrid Reed Bed system (HRBs) is a simple and flexible system. It can be used to cater one single house or the whole neighborhood. Figure 1 shows the HRB system used in this study. It consisted of three beds that were made of fiber glass tanks of the same size $(100 \mathrm{~cm} \mathrm{~W} \times 200 \mathrm{~cm} \mathrm{~L} \mathrm{x} 100 \mathrm{~cm} \mathrm{D})$ and a PVC pipe. The end product is a three-stage CW system with surface-flow (SF), vertical flow (VF), and finally the horizontal-flow (HF) beds. The system was covered with varying gravel sizes as the media, i.e. $30-35 \mathrm{~mm}, 3-5 \mathrm{~mm}$ (river sand), and 10-15 $\mathrm{mm}$, from the bottom to the top, with three days of hydraulic retention time. Such arrangement was applied to determine the most efficient substrate for chemical oxygen demand (COD) removal. Each tank was covered with the substrate up to $40 \mathrm{~cm}$ deep, with the water level retained $10 \mathrm{~cm}$ below the surface of the substrate. The total water depth used for subsurface flow was $30 \mathrm{~cm}$ while the free surface flow was $20 \mathrm{~cm}$ to the surface. Each reed bed tank was planted with Scirpus grossus. It is a type of native Malaysian plant. The experiments were carried out at various parameters, with different configurations, and using continuous flow in order to assess the efficacy of the construct in nutrient removal from the wastewater.

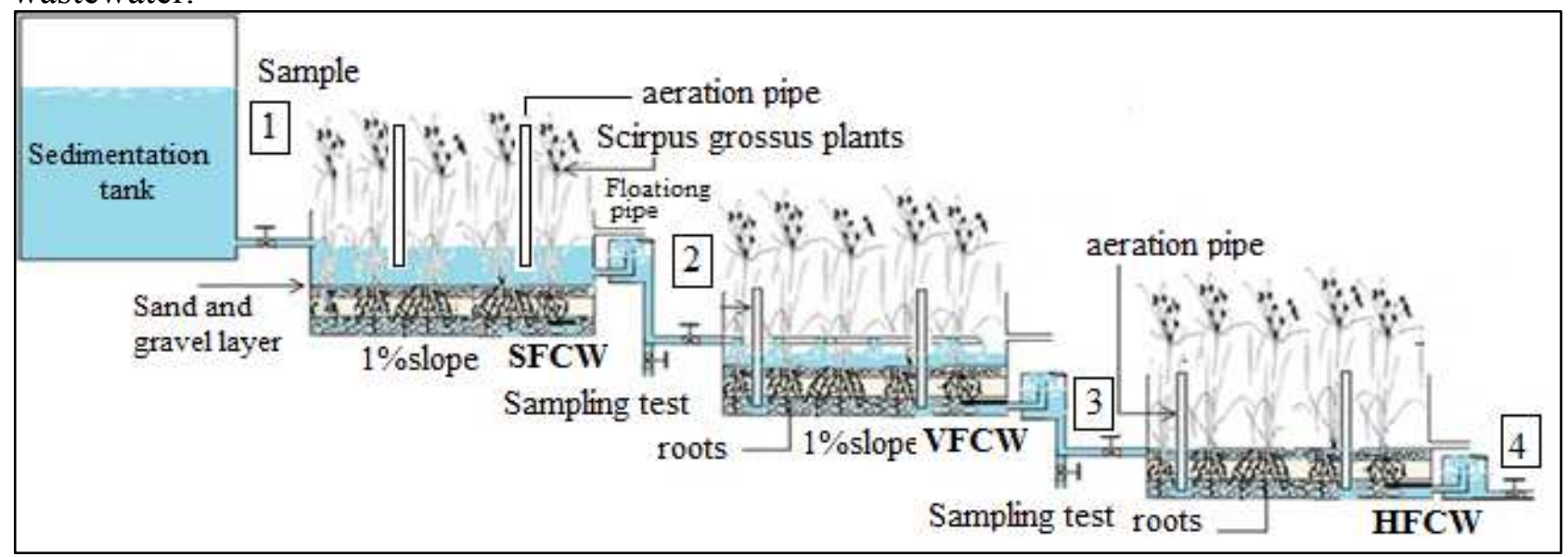

Figure (1) Schematic layout of hybrid reed bed constructed wetland systems

Wastewater from more than 100 households are channeled and collected into a sedimentation tank in Bukit Putri, UKM. For this research, a separate pump was set up to channel the middle level of the 
sedimentation tank into the HRB system for treatment. The middle level was selected to ensure the absence of sludge.

\section{Chemical analysis of COD}

All the tests were carried out in Environmental laboratory, Faculty of Engineering. The test of chemical oxygen demand (COD) is carried according to APHA standard methods for the Examination of water and wastewater 20th Edition. Method 5220c. The test was carried out using DR 3900 Spectrophotometer HACH machine US.

\section{Statistical analysis}

Statistics 21 of Statistical Package for Social Sciences (SPSS) was utilized to analyze the performance of the HRBs in removing the COD. The technique used was the two-way ANOVA analysis of variance.

\section{Result and discussion}

From the physical observation, Scirpus grocuss used in this study, grew well in the hybrid system when loaded with domestic wastewater and produced a vegetation cover the HRB system that gave the wastewater treatment systems a nice appearance. The COD mean removal values for each flow system, with and without plants (control), are depicted in Figure 2 for both hybrid system. The inflow mean COD concentration has seen a reduction from $72.42 \mathrm{mg} / 1$ to only $12.85 \mathrm{mg} / 1$, with $82.96 \%$ average COD removal efficiency. Among all of the concentrations, the maximum removal degradation efficiency percentage was $92 \%$ and $71.79 \%$ by the planted and unplanted hybrid reed bed systems, respectively, Furthermore, the results show that the HF and VF systems, with $36.32 \%$ and $32.45 \%$ respectively, were more reliable than the SF system $(25.34 \%)$ for COD removal, which was also noted by the [9], because in an sub-surface flow system (HF and VF), water must remain below the media surface to minimize human contact. Microbial degradation is largely responsible for the organic matter (COD) removal from the wastewater [10]. The gravel bed and the plant root system provide an excellent condition for microbial microcosms, for the microbes to attach and grow. The oxygen-rich rhizosphere or the root zone effect (RZE) enhances the microbial degradation of organic pollutants in the wastewater. The RZE was suspected to be the main cause for higher efficiency of COD removal in the hybrid reed bed with plants compared to the control HRB system (without plant). The efficient COD removal might have been due to the ability of the root system to filter suspended solids and particulates, and absorb the dissolved nutrients [11].

Based on the t-test analysis, the p-value was 0.001. The two-way ANOVA test was used to analyze the percentage of COD removal in the hybrid systems and to explain the interaction between parameters involved. Percentage of COD removal was statistically significant with days of exposure, with $\mathrm{p}<0.05$. As presented in Table 1, the two-way ANOVA test also showed significant interactions with $\mathrm{p}<0.05$ between ( removal * hybrid system ), ( day * hybrid system * removal ), ( hybrid system * day ) and ( removal * day ). The results showed that the hybrid system in this study has a high efficiency in removing COD from the domestic wastewater. However, minor adjustment on the optimal loading parameters is needed.

Table 1 The statistical analysis on the parameter interactions

\begin{tabular}{|l|c|c|}
\hline Independent variables & $\boldsymbol{F}$ & Sig. \\
\hline Day & 19.4920 & $p<0.05$ \\
\hline Hybrid system & 27.0970 & $p<0.05$ \\
\hline Removal & 331.509 & $p<0.05$ \\
\hline Day * Hybrid system & 30.4690 & $p<0.05$ \\
\hline Day * Removal & 5.84800 & $p<0.05$ \\
\hline Hybrid system * Removal & 3.32600 & 0.041 \\
\hline Day* Hybrid system * Removal & 19.9760 & $p<0.05$ \\
\hline
\end{tabular}




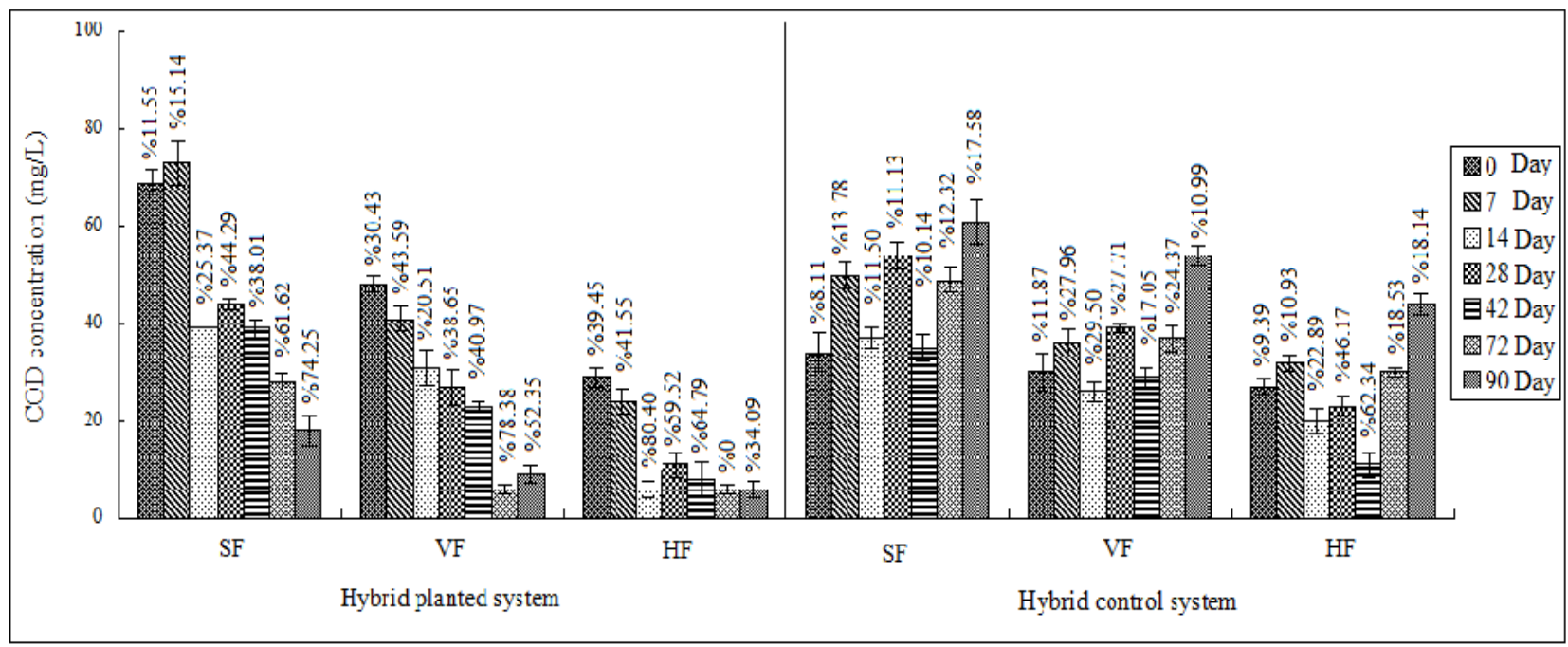

Figure2 COD concentration and its removal percentage for planted and control hybrid systems.

\section{Conclusions}

Notably higher performance was observed for the hybrid systems for different flow direction beds during the $\mathrm{CW}$ operational period for COD with an average removal of more than $82 \%$ for COD. These results indicate that the constructed wetland using Scirpus grossus plant has a high effectiveness for treating domestic wastewater. The planted HRB system have performed better in removing COD than the control beds giving evidence that $\mathrm{CW}$ is possible to be applied in sewage treatment.

\section{Acknowledgments}

The authors would like to thank Universiti Kebangsaan Malaysia, Tasik Chini Research Centre, and Malaysian Ministry of Science, Technology and Innovation for supporting this research project under a Research Grant of 02-01-02-SF1045, and the Libya Directorate General of Higher Education for providing a doctoral scholarship for the first author.

\section{References}

[1] D. P. L. Rousseau, E. Lesage and A. Story, Constructed wetlands for water reclamation, Desalination, 218 (2008) 181-189.

[2] R. H. Kadlec and S. D. Wallace, Treatment Wetlands second edition, CRC Press, Taylor and Francis Group ,Florida, USA. ISBN 978 (2009) 56670-526-4.

[3] A. Karathanasis, C. Potter and M. Coyne, Vegetation effects on fecal bacteria, BOD, and suspended solid removal in constructed wetlands treating domestic wastewater, Ecol En. 20 (2004) 157-69.

[4] J. Lloyd, D. Klessa, D. Parry, P. Buck and N. Brown, Stimulation of microbial sulfate reduction in a constructed wetland: microbiological and geochemical analysis, Water Res. 38 (2004) 1822-1830.

[5] S. Jing, Y. Lin, D. Lee and T. Wang, Microcosm wetland for wastewater treatment with different hydraulic loading rates and 'macrophytes, J Environ Qual. 31 (2002) 690-96.

[6] M. Kaseva, Performance of a sub-surface flow constructed wetland in polishing pre-treated wastewater - a tropical case study, Water Res. 38 (2004) 681-687.

[7] K.R. Edwards, H. Cizkova, K. Zemanova and H. Santruckova, Plant growth and microbial processes in a constructed wetland planted with Phalaris arundinacea, Ecol. Eng. 27 (2006) 153-165. 
[8] G. Langergraber, The role of plant uptake on the removal of organic matter and nutrients in subsurface flow constructed wetlands: a simulation study, Water Sci. Technol. 51 (2005) 213-223.

[9] USEPA.. Policy and Program Requirements for the Mandatory Agency-Wide Quality System, US EPA Order 5360.1 A2, 2000b.

[10] P. Gikas, E. Ranieri, and G. Tchobanoglous, BTEX removal in pilot-scale horizontal subsurface flow constructed wetlands, Desalination and Water Treatment 51 (2013) 3032-3039.

[11] R. D. Sooknah and A. C. Wilkie, Nutrient removal by floating aquatic macrophytes cultured in anaerobically digested flushed dairy manure wastewater, Ecol. Eng. 22 (2004) 27-42. 